\title{
VARIATIONS IN THE CARDIAC OUTPUT OF MAN
}

\author{
V. The Cardiac Output of Man During the Malatse and \\ Pyrexia Following the Injection of Typhoid Vaccine
}

\author{
BY ARTHUR GROLLMAN
}

\begin{abstract}
(From the Physiological Laboratory, School of Medicine, The Johns Hopkins University, Baltimore)
\end{abstract}

(Received for publication May 23, 1929)

While investigating the effect of the environmental temperature on the cardiac output of man, it was observed that the values obtained on a subject who, several hours previous to the experiment, had received an injection of typhoid vaccine, were much higher than the values which had previously been obtained in repeated determinations on the same individual. This unexpected increase in cardiac output was attributed to the effect of the reaction to the foreign protein injected and it was thought worth while to extend the observation on a number of other individuals. The problem seemed of interest because it enabled one to determine the reaction of the heart to slight degrees of malaise and fever. Since the nature of this reaction to foreign protein, as observed after the injection of typhoid vaccine, is in many respects similar to the reaction following certain infectious processes, the results should also throw light on the cardiac changes which might be expected to accompåny these conditions. Exact data of the clinical variations of the cardiac output are extremely rare because of the great inaccuracies and difficulties which attend such determinations, and hence any additional data bearing on this problem are highly desirable.

\section{METHODS}

The present determinations of the cardiac output were carried out by the use of acetylene (1) in the method previously described (2). By the use of this gas an extremely high degree of accuracy is easily obtainable and the results quoted should not be in error beyond \pm 5 per cent. 
All of the subjects used in the present investigation were young, healthy medical students, who were sufficiently well acquainted with the general procedure to avoid the vitiating effects of any excitement or other psychic disturbance. In all, except two, of the cases studied data were available for the values of the various functions studied before the injection. The control determinations on any one individual were always made at the same time of the day as were the determinations after the injections in order to avoid any diurnal variations of the cardiac output. After at least one-half hour's rest in a steamer chair, the various determinations were performed, with the precautions described in previous studies $(3,4)$.

The subjects for the present study were selected from those who had shown a rather severe reaction to a previous injection of the typhoid vaccine. Except in the case of subjects 6 and 7, the results refer to the effects of the second of a total of three weekly injections, in which one billion typhoid bacilli were injected in the usual manner into the triceps muscle of the arm. The results on subject 6 were obtained after the first of the three injections (500 million bacilli) and those on subject 7 were obtained after the third injection.

In calculating the cardiac output during fever, it is necessary to take into account the diminution in solubility of the foreign gas used, as a result of the increased temperature of the blood. As previously noted (1) the temperature of this blood is not exactly known but has been estimated for the normal condition as $37.5^{\circ} \mathrm{C}$. The temperature coefficient for the solubility of acetylene in blood is about $12 \mathrm{cc}$. per liter per degree centigrade (5). Hence, by subtracting this value from 740 , the solubility of acetylene in blood at $37.5^{\circ}(6)$, for every degree centigrade rise in body temperature, one obtains a value which is to be substituted in the equation used in calculating the heart output during pyrexia (1).

\section{RESULTS}

The results of this study are given in table 1 .

The most complete series of results are those quoted on Subject 1 . In this case determinations were made at intervals during the first 24 hours after the injection. This subject had a particularly violent reaction to the vaccine. Two hours after the injection (table 1 and 
TABLE 1

The effect of the injection of typhoid vaccine on the cardiac output, pulse rate, blood pressure, temperature (oral), and oxygen consumption

\begin{tabular}{|c|c|c|c|c|c|c|c|}
\hline 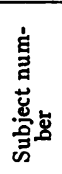 & Condition & 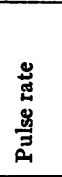 & 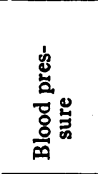 & 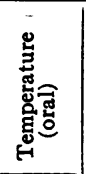 & 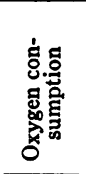 & 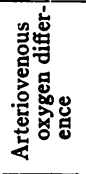 & 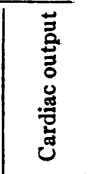 \\
\hline \multirow{7}{*}{1} & & & & ${ }^{\circ} \mathrm{F}$. & $\begin{array}{l}\text { cc. per } \\
\text { minute }\end{array}$ & $\begin{array}{l}\text { cc.per } \\
\text { liter }\end{array}$ & $\mid \begin{array}{c}\text { Liters per } \\
\text { minute }\end{array}$ \\
\hline & 24 hours before injection & 74 & $105 / 75$ & 97.6 & 240 & 63 & 3.81 \\
\hline & $\begin{array}{l}2 \text { hours after injection; sore } \\
\text { arm; vague soreness of joints; } \\
\text { not perceptibly ill }\end{array}$ & 86 & $109 / 80$ & 98.7 & 281 & 60 & 4.68 \\
\hline & $\begin{array}{l}7 \text { hours after injection; general } \\
\text { malaise }\end{array}$ & 102 & $118 / 83$ & 100.7 & 322 & 50 & 6.44 \\
\hline & $\begin{array}{l}12 \text { hours after injection; ex- } \\
\text { tremely ill; practically pros- } \\
\text { trate }\end{array}$ & 120 & $124 / 70$ & 103.8 & 363 & 75 & 4.84 \\
\hline & $\begin{array}{l}19 \text { hours after injection; feeling } \\
\text { weak and generally ill but } \\
\text { much improved over time of } \\
\text { preceding determination }\end{array}$ & 100 & $108 / 65$ & 101.1 & 330 & 65 & 5.09 \\
\hline & 5 days after injection & 70 & $103 / 72$ & 97.5 & 238 & 63 & 3.78 \\
\hline \multirow{4}{*}{2} & 24 hours before injection & 78 & $108 / 70$ & 97.3 & 284 & 63 & 4.51 \\
\hline & $\begin{array}{l}3 \text { hours after injection; no sub- } \\
\text { jective reactions }\end{array}$ & 80 & $112 / 71$ & 97.7 & 280 & 55 & 5.09 \\
\hline & $\begin{array}{l}21 \text { hours after injection; head- } \\
\text { ache and slight malaise }\end{array}$ & 88 & $103 / 70$ & 98.5 & 300 & 60 & 5.00 \\
\hline & 1 week after injection & 76 & $100 / 60$ & 97.7 & 288 & 65 & 4.43 \\
\hline \multirow{3}{*}{3} & Before injection & 74 & $116 / 74$ & 97.8 & 295 & 60 & 4.92 \\
\hline & $\begin{array}{l}23 \text { hours after injection; malaise } \\
\text { and headache }\end{array}$ & 90 & $158 / 84$ & 99.8 & 318 & 60 & 5.30 \\
\hline & 1 week after injection & 80 & $142 / 82$ & 97.8 & 308 & 62 & 4.97 \\
\hline \multirow[t]{2}{*}{4} & $\begin{array}{l}18 \text { hours after injection; slight } \\
\text { feeling of malaise }\end{array}$ & 90 & $106 / 69$ & 98.8 & 239 & 52 & 4.60 \\
\hline & 1 week after injection & 68 & $101 / 64$ & 97.1 & 230 & 56 & 4.11 \\
\hline \multirow[t]{2}{*}{5} & $\begin{array}{l}21 \text { hours after injection; head- } \\
\text { ache and general malaise }\end{array}$ & 84 & $98 / 68$ & 99.1 & 282 & 60 & 4.70 \\
\hline & 6 days after injection & 62 & $110 / 73$ & 97.1 & 264 & 65 & 4.06 \\
\hline \multirow{3}{*}{6} & Before injection & 70 & $103 / 65$ & 97.5 & 245 & 62 & 3.95 \\
\hline & $\begin{array}{l}18 \text { hours after injection; very } \\
\text { slight malaise }\end{array}$ & 80 & $117 / 70$ & 98.0 & 274 & 66 & 4.15 \\
\hline & 1 week after injection & 62 & $105 / 65$ & 97.6 & 236 & 60 & 3.93 \\
\hline
\end{tabular}




\begin{tabular}{|c|c|c|c|c|c|c|c|}
\hline 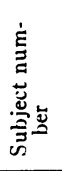 & Condition & $\begin{array}{l}\text { 岕 } \\
\text { 品 } \\
\frac{3}{3}\end{array}$ & 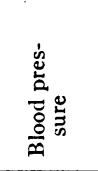 & 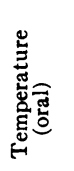 & 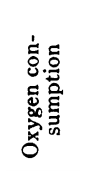 & 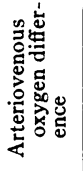 & 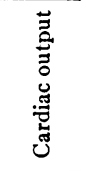 \\
\hline \multirow{4}{*}{7} & & & & ${ }^{\circ} \mathrm{F}$ & $\begin{array}{c}c c \text { per } \\
\text { minule }\end{array}$ & $\begin{array}{c}c c \text {. per } \\
\text { liter }\end{array}$ & $\begin{array}{l}\text { liters per } \\
\text { minute }\end{array}$ \\
\hline & Before injection & 60 & $105 / 70$ & 98.0 & 220 & 63 & 3.49 \\
\hline & $\begin{array}{l}20 \text { hours after injection; very } \\
\text { slight malaise }\end{array}$ & 82 & $108 / 65$ & 98.3 & 225 & 62 & 3.63 \\
\hline & 1 week after injection & 62 & $104 / 68$ & 98.0 & 220 & 58 & 3.80 \\
\hline \multirow{3}{*}{8} & Before injection & 70 & $105 / 70$ & 97.6 & 240 & 60 & 4.00 \\
\hline & 3 hours after injection; slight & 80 & $117 / 82$ & & 280 & 58 & 4.83 \\
\hline & 1 week after injection & 70 & $105 / 70$ & 97.5 & 238 & 60 & 3.97 \\
\hline
\end{tabular}

fig. 1) marked changes from the resting values of the normal were already obtained. At this time there was a vague sense of soreness in the joints but no severe subjective symptoms. Nevertheless, there was a mild pyrexia, an increase of 20 per cent in the oxygen consumption, and a corresponding increase in the cardiac output. The heart may be considered at this time as merely responding to the increased metabolism, with but slight diminution in the oxygen utilization of the blood.

At the time of the second determination, the subject was feeling quite ill and all the functions studied were greatly elevated. The third determination on this subject was made at the height of his illness, 12 hours after the injection. The subject was practically prostrate. Although the pulse, blood pressure, body temperature, and oxygen consumption were now at their maxima, the cardiac output was greatly diminished over its previous value, when the subject was less ill. This change was brought about by a great increase in the oxygen utilization of the blood. This also occurred in the case of the other subjects studied. Thus in the case of the second experiment on subject 2, the cardiac output is slightly greater than that of the third experiment although the malaise, pulse, fever, and oxygen consumption were greater in the latter experiment. It thus appears that the change in malaise and pyrexia and the increase in cardiac 
output do not occur together. Instead, the greatest increase in cardiac output occurred soon after the injection when the pyrexia and malaise were at a minimum. About 15 to 24 hours after the injection when the subjective feelings were severe, the cardiac output showed lesser changes than it had previously. We must thus conclude that

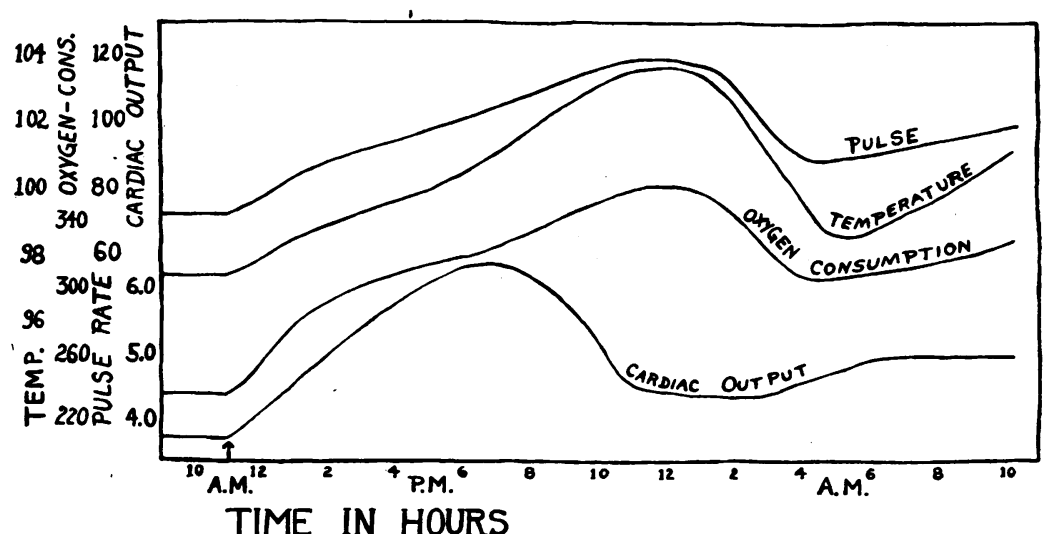

Fig. 1. Graphic Representation of the Changes in Pulse Rate, Temperature (Orat), Oxygen Consumption and Cardiac Output During the 24

Hours Following the InJection of 1 cc. of Typhom Vaccine

The axis of abscissae represents the time of the day in hours. At the point indicated by the arrow (11:00 a.m.), the injection was made. The horizontal portions of the curves represent the normal values of the various functions studied as found previous to the injection. The cardiac output is expressed in terms of liters per minute, the oxygen consumption in cc. per minute, and the temperature in degrees Fahrenheit. The subject's malaise followed the temperature, pulse rate, and oxygen-consumption curves, being at its maximum at midnight, 13 hours after the injection. The malaise then subsided but increased again during the following morning and continued throughout the following day and night with a fever of over $100^{\circ}$.

the injection of foreign protein causes at first an increase of the cardiac output which then partly subsides during the later stages of the reaction when the subjective feelings are at their maximum.

These results as obtained on subject 1 during the first 24 hours following the injection, are graphically represented in figure 1 .

In order to compare the values of the cardiac output and other 
functions studied during the subject's 'reaction to the typhoid vaccine with the normal values of these functions, it was necessary to obtain data on days before the injection or after recovery. It may be objected that such comparisons are not permissible since the heart output is usually considered as varying widely from day to day. This objection, however, is invalid, for the concept of a variable cardiac output under normal conditions is based upon erroneous data. Unpublished results ${ }^{1}$ by the author have shown that if proper precautions be taken to avoid such factors as psychic disturbances, temperature variations, food, etc., constant results may be obtained from day to day. Hence the results obtained during the malaise following the injection of the vaccine may be compared to those obtained when the subject was normal, despite the fact that the two sets of data were obtained on different days. This is further demonstrated by the close agreement between the results obtained on the day before the injection and those obtained some days later (table 1). Except in the case of subjects 1 and 2, the data were obtained in the morning on the subject's arrival at the laboratory in the basal condition. When basal determinations were impossible as in the case of the determinations on subjects 1 and 2, the control experiments were made at the same hour of the day and under the same conditions as the experiments after the injection. Such determinations were always made some hours after the ingestion of a very light meal, under which conditions as has been demonstrated (10), the value of the cardiac output is essentially that of the basal condition.

\section{DISCUSSION}

Inspection of table 1 and figure 1 shows the marked increases in the pulse rate which follow the injection of typhoid vaccine This increase in pulse rate was found to follow the subjective feelings of malaise and the pyrexia. Since the cardiac output, as stated above, did not follow the malaise and pyrexia except during the early period

\footnotetext{
${ }^{1}$ Further evidence for this is furnished by the demonstration (11) of the possibility of predicting the cardiac output of normal individuals in the truly basal condition. As has been previously demonstrated (11) one can judge, from a single determination of the cardiac output, the degree of its abnormality.
} 
of the reaction, it is evident that there is a marked variation in the output per beat of the heart. During the early period of the reaction, there was, in general, a marked increase in the output per beat but at the height of the malaise, this increase was diminished.

In general the blood pressure, after the injection of typhoid vaccine, shows only a moderate degree of variation from the normal. There was, except in subject 5 , a rise in the systolic pressure and usually a slight rise in the diastolic pressure, although the latter was at times diminished.

The degree of pyrexia followed closely the subjective symptoms. The increase in oxygen consumption, in turn, was proportional to the degree of pyrexia, as noted by Du Bois and his collaborators $(7,8)$.

The observed changes in cardiac output can be explained as resulting either from a direct stimulation of the heart or as a secondary effect of the increased metabolism. The relatively slight changes in the arterio-venous oxygen differences would support the view that the second of these factors is responsible for the cardiac changes. Hence, the increased cardiac outputs following the injection of typhoid vaccine are to be considered as an attempt on the part of the organism to maintain a constant internal environment, in so far as the oxygen utilization of the tissues is concerned. At the height of the malaise, the relative decrease in the cardiac output may be related, in part at least, to the decrease in the volume of blood flowing through the periphery (9). This decrease in the size of the peripheral vascular bed, would result in a great increase in the blood pressure were the latter not avoided by a diminution in the cardiac output.

Bjerlöw and Liljestrand (12) found, in four cases of experimentally induced recurrent fever, an increase in the cardiac output proportional to the increased oxygen consumption encountered during the fever. This is in accord with the present findings during the early stages of fever. These authors failed to note, however, the failure of the cardiac output to follow the changes in oxygen consumption during the later stages of fever, as shown in the present work. Due to the protracted nature of the fevers encountered clinically, this latter state of affairs is probably of greater practical significance than the changes occurring during the very early stages of fever. 


\section{SUMMARY}

A study was made of the cardiac output, pulse rate, blood pressure, temperature, and oxygen consumption of 8 individuals after the intramuscular injection of typhoid vaccine. The cardiac output was found to be greatly elevated soon after the injection but did not follow the malaise and pyrexia throughout the course of the reaction. At the height of the malaise the cardiac output, although still elevated above the normal, was nevertheless less than it was during the preceding period. The pulse rate and oxygen consumption varied uniformly with the degree of malaise and the pyrexia. The physiological implications of these results are discussed.

\section{BIBLIOGRAPHY}

1. Grollman, A., Am. J. Physiol., 1929, lxxxviii, 432. The Determination of the Cardiac Output of Man by the Use of Acetylene.

2. Marshall, E. K., and Grollman, A., Am. J. Physiol., 1928, lxxxvi, 117. A Method for the Determination of the Circulatory Minute Volume in Man.

3. Grollman, A., Am. J. Physiol., 1928, lxxxvi, 285. The Effect of Variation in Posture on the Output of the Human Heart.

4. Grollman, A., Am. J. Physiol., 1929, lxxxix, 157. Physiological Variations in the Cardiac Output of Man. II. Changes in the Cardiac Output, Metabolism, Blood Pressure and Pulse Rate of Man Following the Ingestion of Fluids.

5. Schoen, R., Ztschr. f. physiol. Chemie., 1923, cxxvii, 243. Die Löslichkeit von Acetylen in Wasser und Blut.

6. Grollman, A., J. Biol. Chem., 1929, lxxxii, 317. The Solubility of Gases in Blood and Blood Fluids.

7. Du Bois, E. F., In Endocrinology and Metabolism, edited by Barker, L. F., New York and London, 1922, iv, 95.

8. Barr, D. P., Cecil, R. L., and Du Bois, E. F., Arch. Int. Med., 1922, xxix, 608. Clinical Calorimetry. XXXII. Temperature Regulation After the Intravenous Injection of Proteose and Typhoid Vaccine.

9. Hewlett, A. W., Heart, 1911, ii, 230. The Effect of Room Temperature Upon the Blood Flow in the Arm, with a Few Observations on the Effect of Fever.

10. Grollman, A., Am. J. Physiol., 1929, lxxxix, 366. Physiological Variations in the Cardiac Output of Man. III. The Effect of the Ingestion of Food on the Cardiac Output, Pulse Rate, Blood Pressure, and Oxygen Consumption of Man.

11. Grollman, A., Am. J. Physiol., 1929, xc, 210. Physiological Variations in the Cardiac Output of Man. VI. The Value of the Cardiac Output of the Normal Individual in the Basal Resting Condition.

12. Bjerlöw, H., and Liljestrand, G., Acta Med. Scandinavica, 1927, lxvii, 5. The Resting Minute Volume of the Heart in Man during Recurrent Fever. 